\title{
Anticaries Effect of Ethanol Extract of Terminalia chebula
}

\author{
Moonkyung Lee and Young Sun Hwang ${ }^{\dagger}$ \\ Department of Dental Hygiene, College of Health Science, Eulji University, Seongnam 13135, Korea
}

\begin{abstract}
Background: Dental caries is mainly composed of various cellular components and is deposited around the tooth surface and gums, causing a number of periodontal diseases. Streptococcus mutans is commonly found in the human oral cavity and is a significant contributor to tooth decay. The use of antibacterial ingredients in oral hygiene products has demonstrated usefulness in the management of dental caries. This study investigated the anticaries effect of the ethanol extract of Terminalia chebula (EETC) against $S$. mutans and their cytotoxicity to gingival epithelial cells.

Methods: The EETC was prepared from $T$. chebula fruit using ethanol extraction. Disk diffusion, minimum inhibitory concentration (MIC), minimum bactericidal concentration (MBC), and colony forming unit (CFU) were analyzed to investigate the antimicrobial activity of the EETC. Glucan formation was measured using the filtrate of the bacterial culture medium and sucrose. Gene expression was analyzed using reverse transcription-polymerase chain reaction (RT-PCR). Cytotoxicity was analyzed via the 3-(4,5-dimethylthiazol-2-yl)-2,5-diphenyl tetrazolium bromide assay.

Results: The antibacterial activity of the EETC was explored using disc diffusion and CFU measurements. The MIC and MBC of the EETC were 10 and $20 \mu \mathrm{g} / \mathrm{ml}$, respectively. EETC treatment decreased insoluble glucan formation by $S$. mutans enzymes and also resulted in reduced glycosyltransferase $B(g t f B), g t f C, g t f D$, and fructosyltransferase $(f t f)$, expressions on RT-PCR. In addition, at effective antibacterial concentrations, EETC treatment was not cytotoxic to gingival epithelial cells.

Conclusion: These results demonstrate that the EETC is an effective anticaries ingredient with low cytotoxicity to gingival epithelial cells. The EETC may be useful in antibacterial oral hygiene products for the management of dental caries.
\end{abstract}

Key Words: Antibacterial agents, Dental caries, Oral hygiene, Dental plaque, Streptococcus mutans

\section{Introduction}

Dental caries is caused by plaque, a bacterial colony deposited on the surface of the teeth and gum tissue. Dental plaque removal is a vital aspect of oral health management. According to the Health Care Big Data Open System from the Health Insurance Review and Assessment Service in Korea, in 2010, the number of outpatients with dental caries (K02) was ranked 7th with a total of 537 million, but in 2019 it was ranked 4th with a total of 645 million. Along with the increase in the number of outpatients, medical care benefits for dental caries also increased from 2,420 billion won in 2010 to 5,397 billion won in 2019 ${ }^{1)}$. These results suggested that current oral health management regimes are fundamentally lacking and require reinspection.

The oral cavity is a suitable environment for bacterial growth and propagation. The presence of bacteria in the mouth stimulates the formation of dental plaque, which accumulates in both hard and soft tissues as dental calculus. Tooth decay is caused by the production of insoluble saccharide polymers and organic acids by oral bacteria. Glycosyltransferase (GTase) and fructosyltransferase (FTase) convert saccharides to insoluble polymers, such as glucan and fructan ${ }^{2}$. These insoluble polymers adhere to the tooth enamel surface and facilitates stable bacteria growth and the incorporation of many types of bacteria. The locally attached bacteria then produce persistent 
organic acids through glycolysis, which acidifies the environment around the tooth surface, thereby leading to demineralization ${ }^{3)}$. Streptococcus spp. and Lactobacillus spp. are the bacteria most responsible for tooth decay ${ }^{4)}$, among these, Streptococcus mutans is one of the main causes of tooth decay. S. mutans is an acid-resistant bacterium that can contribute to sustained demineralization in the acidified environment of the dental plaque.

The fruit of the Terminalia chebula tree has been demonstrated a range of biological actions, including anti-diabetic, anti-mutagenic, antioxidant, anti-fungal, anti-bacterial, and anti-viral effects ${ }^{5,6}$. The anti-bacterial effects of $T$. chebula fruit extracted according to various methods have been reported against Salmonella typhi, Staphylococcus epidermidis, Staphylococcus aureus, Bacillus subtilis, and Pseudomonas aeruginosa ${ }^{7}$. The anti-bacterial effect of $T$. chebula fruit extracts against $S$. mutans has also been reported ${ }^{8}$, however, investigation into the genetic mechanisms of the anti-caries activity are insufficient. In addition, the safety of the extract in the oral environment also requires investigation before their use in oral healthcare products, as is their intended application.

The present study assessed the anticaries effects of an ethanol extract of T. chebula (EETC) against S. mutans and investigated the genetic mechanisms underlying the anticaries activity. Our data indicate that the EETC is safe for gingival epithelial cells and, through its antibacterial effects, is an effective anti-caries agent.

\section{Materials and Methods}

\section{Plant material}

The EETC was obtained from COSMAX Inc. R\&I Center (Seongnam, Korea). The fruits powder was thoroughly extracted using $70 \%$ ethanol, filtered with Whatman filter paper, and concentrated using a rotary evaporator. The extracts were stored in a refrigerator until further use.

\section{Bacterial culture}

S. mutans KCTC3065 was obtained from the Korean Collection for Type Cultures at the Korea Research Institute of Bioscience and Biotechnology (Daejeon,
Korea) and cultured in either brain-heart infusion (BHI) broth (Becton, Dickinson and Company, Baltimore, MD, USA) or BHI agar at $37^{\circ} \mathrm{C}$.

\section{Drug susceptibility test}

Drug susceptibility was assessed using the disc diffusion method. Briefly, a bacterial suspension in agarose solution was inoculated on BHI agar plates and the gel was allowed to solidify completely at room temperature. Whatman filter discs with infused with drugs were placed on the plates and cultured for 24 hours. Drug susceptibility was assessed by linear fitting of the squared radius (diameter in $\mathrm{mm}$ ) of the inhibition zones.

\section{Minimum inhibitory concentrations (MICs) and minimum bactericidal concentrations (MBCs)}

The MICs for the EETC were determined in triplicate using the broth dilution method after incubation at $37^{\circ} \mathrm{C}$ for 24 hours. Briefly, the EETC was added to $10 \mathrm{ml}$ volumes of liquid medium resulting in $0,0.1,0.5,1,5,10$, $15,20,25$, and $30 \mu \mathrm{g} / \mathrm{ml}$ solutions, into which the cultured strain was inoculated such that the absorbance was 0.1 at $600 \mathrm{~nm}$. After 24 hours, the absorbance of the culture medium was measured at $600 \mathrm{~nm}$. The concentration of the EETC with an absorbance of $0.1 \pm 0.01$ or less was defined as the MIC of the EETC. To determine the MBC for the EETC, bacteria were cultured for 24 hours in a liquid medium containing a 10 to $10^{-7}$ serial dilution of the EETC. The diluted bacterial solutions $(100 \mu \mathrm{l})$ were smeared on agar plates and incubated for 3 days before counting the number of colonies. The number of bacteria per $100 \mathrm{ml}$ was estimated by inverting the dilution factor. We defined the $\mathrm{MBC}$ as the minimum concentration of the extract required to kill $99.99 \%$ of the bacterial cells compared to the control group.

\section{Colony forming units (CFUs)}

The number of viable cells was measured by a CFU assay. $S$. mutans was cultured until the absorbance of 600 $\mathrm{nm}$ was 0.4 . A culture medium $(100 \mu \mathrm{l})$ was added to 900 $\mathrm{ml}$ liquid medium to which the EETC was added $(0,0.1$, $0.5,1,5,10,15$, and $20 \mu \mathrm{g} / \mathrm{ml}$ ) to make a 10 -fold diluted 
bacterial solution. The dilution was repeated to $10^{-5}$. The diluted bacterial solutions $(100 \mu \mathrm{l})$ were smeared on agar plates, incubated for 3 days, and the colonies counted.

\section{Glucan formation}

S. mutans was cultured in liquid media before being centrifugated at $10,000 \mathrm{rpm}$ for 30 minutes. The supernatant was then filtered through a $0.22 \mathrm{~mm}$ filter. Next, the filtrate was prepared using an Amicon Ultra Centrifugal Filter (MWCO 30kDa, Cat. No. UFC903008; Millipore, Merck KGaA, Darmstadt, Germany) and used as a bacterial enzyme solution containing GTase. The enzyme solution and/or EETC $(200 \mu \mathrm{l})$ was added to 800 $\mathrm{ml}$ of the sucrose-containing substrate solution (sucrose $12.5 \mathrm{mg}, \mathrm{NaN} 30.25 \mathrm{mg} / \mathrm{ml}$ of $50 \mathrm{mM}$ potassium phosphate buffer $[\mathrm{pH} 6.5])$ to make a $1 \mathrm{ml}$ reaction solution, which was incubated at $37^{\circ} \mathrm{C}$ for 36 hours. The reaction solution was then centrifugated and the supernatant was discarded. Thereafter, $4 \mathrm{ml}$ of $50 \mathrm{mM}$ potassium phosphate buffer $(\mathrm{pH}$ 6.5) was added and the solution was sonicated for 5 minutes. The absorbance of the solution was measured at $550 \mathrm{~nm}$.

\section{Reverse transcription-polymerase chain reaction (RT-PCR)}

Total RNA was isolated using the TRIzol reagent (Invitrogen, Carlsbad, CA, USA) according to the manufacturer's instructions. First-strand cDNA synthesis was performed using $2 \mathrm{mg}$ of total RNA and Promega's reverse transcription system (Madison, WI, USA). The primer sequences and annealing temperatures for RT-PCR are shown in Table 1. Thirty cycles of PCR amplification were carried out in a reaction mixture containing $0.5 \mu \mathrm{g}$ first-strand cDNA and 10 pmol primers. The amplified PCR product was electrophoresed on a $2 \%$ agarose gel in $1 \times$ tris-borate-ethylenediaminetetraacetic acid buffer containing ethidium bromide and visualized using a Gel Doc 2000 system (BioRad Laboratories, Hercules, CA USA). The images were analyzed using the ImageJ program in the same pixel area (National Institutes of Health, Bethesda, MD, USA). The primers were selected using the OligpAnalyzer Tool (https://sg.idtdna.com) based on the GC content and melting temperature, and synthesized by Bioneer (Daejeon, Korea).

\section{The 3-(4,5-dimethylthiazol-2-yl)-2,5-diphenyl tetrazolium bromide (MTT) assay}

Human gingival epithelial cells were grown in DMEM/F12 (3:1) supplemented with 10\% FBS, $1 \times 10^{-10}$ M cholera toxin, $0.4 \mu \mathrm{g} / \mathrm{ml}$ hydrocortisone, $5 \mu \mathrm{g} / \mathrm{ml}$ insulin, $5 \mu \mathrm{g} / \mathrm{ml}$ transferrin and $2 \times 10^{-11} \mathrm{M}$ triiodothyronine at $37^{\circ} \mathrm{C}$ in a humidified atmosphere of $5 \% \mathrm{CO}_{2}$. Cells $\left(5 \times 10^{3}\right.$ cells/well) were seeded into $96-$ well culture plates and allowed to adhere overnight. These cells were treated with various concentrations of EETC for 24 or 48 hours. Viable cells were detected by incubating with a $5 \mu \mathrm{g} / \mathrm{ml}$ MTT solution for an additional 4 hours at $37^{\circ} \mathrm{C}$, followed by the dissolution of the produced formazan product in the cells with $100 \mathrm{ml}$ of dimethyl sulfoxide. Absorbance was measured at $570 \mathrm{~nm}$ using a microplate reader $\left(\right.$ Synergy ${ }^{\mathrm{TM}}$ HTX Multi-Mode Microplate Reader; BioTek, Winooski, VT, USA). Human gingival epithelial cells at passages 8 to 10 were obtained from the College of Dentistry in Yonsei University (Seoul, Korea) ${ }^{9}$.

Table 1. Primer Sequence and Annealing Temperature for Reverse Transcription-Polymerase Chain Reaction

\begin{tabular}{|c|c|c|}
\hline Target gene & Primer sequence & Annealing temperature $\left({ }^{\circ} \mathrm{C}\right)$ \\
\hline Glucosyltransferase B & $\begin{array}{l}\text { Sence; 5'-AGCAATGCAGCCAATCTACAAAT-3' } \\
\text { Antisence; 5'-ACGAACTTTGCCGTTATTGTCA-3' }\end{array}$ & 60 \\
\hline Glucosyltransferase C & $\begin{array}{l}\text { Sence; 5'-GGTTTAACGTCAAAATTAGCTGTATTAGC-3' } \\
\text { Antisence; 5'-CTCAACCAACCGCCACTGTT-3' }\end{array}$ & 60 \\
\hline Glucosyltransferase D & $\begin{array}{l}\text { Sence; 5'-ACAGCAGACAGCAGCCAAGA-3' } \\
\text { Antisence; 5'-ACTGGGTTTGCTGCGTTTG-3' }\end{array}$ & 60 \\
\hline Fructoxyltransferase & $\begin{array}{l}\text { Sence; 5'-AAATATGAAGGCGGCTACAACG-3' } \\
\text { Antisence; 5'-CTTCACCAGTCTTAGCATCCTGAA-3', }\end{array}$ & 60 \\
\hline GAPDH & $\begin{array}{l}\text { Sence; 5'-CCGCCTACTGCCCACTGCCACCAC-3' } \\
\text { Antisence; 5'-TCCATCCACTATGTCAGCAGGTCC-3', }\end{array}$ & 55 \\
\hline
\end{tabular}




\section{Statistical analysis}

Statistical analyses were conducted using InStat GraphPad Prism ver. 5.01 (GraphPad Software, Inc., San Diego, CA, USA). Non-parametric Kruskal-Wallis tests with Dunn's post-hoc analysis were used for multiple comparisons. The results are presented as mean \pm standard error of the mean. Asterisks indicate statistical significance. Statistical significance was set at $\mathrm{p}<0.05$.

\section{Results}

\section{The EETC inhibits $S$. mutans growth}

The disk diffusion method was used to verify the growth inhibition effects of the EETC against $S$. mutans. S. mutans was cultured on an agar plate with a paper disk containing the EETC. As shown in Fig. 1A, 5 to $20 \mu \mathrm{g} / \mathrm{ml}$ EETC strongly inhibited $S$. mutans growth. The diameter of the clear zone where the $S$. mutans growth was suppressed according to the EETC concentrations are shown in Table 2. The clear zones measured $1.7 \pm 0.12,4.2 \pm 0.49,10.1 \pm$ 0.72 , and $18.6 \pm 0.14 \mathrm{~mm}$ for $5,10,15$, and $20 \mu \mathrm{g} / \mathrm{ml}$ EETC, respectively.

\section{S. mutans growth inhibition according to EETC concentration}

To observe the growth inhibition according to EETC concentration, $S$. mutans cultured in 0 to $20 \mu \mathrm{g} / \mathrm{ml}$ EETC was diluted 10-fold and cultured on agar plates to count the number of colonies. As shown in Fig. 1B, the number of colonies decreased with increasing EETC concentration. For EETC concentrations of $0,0.1,0.5,1,5,10,15$, and $20 \mu \mathrm{g} / \mathrm{ml}$, the colony counts were 4.98, 5.02, 4.99, 4.78, $4.66,1.89,1.14$, and $0.31 \log \mathrm{CFU} / \mathrm{ml}$, respectively.

\section{The MIC and MBC of the EETC}

To measure the MIC required for the EETC to inhibit $S$. mutans growth, absorbance was measured after culturing S. mutans in a medium containing 0 to $30 \mu \mathrm{g} / \mathrm{ml}$ of the EETC. To determine the MBC, $S$. mutans cultured in medium containing the EETC was diluted 10-fold and cultured on an agar plate to count the number of colonies. The MIC and MBC were determined to be $10 \mu \mathrm{g} / \mathrm{ml}$ and $20 \mu \mathrm{g} / \mathrm{ml}$, respectively.

\section{Effect of the EETC on glucan formation by S. mutans}

Glucan formation was analyzed in reaction mixtures with the filtrates of $S$. mutans culture medium and sucrose.
A

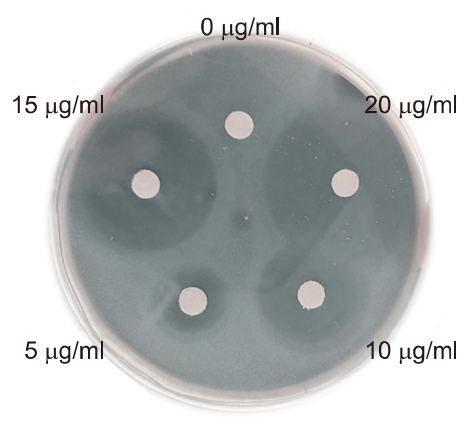

B

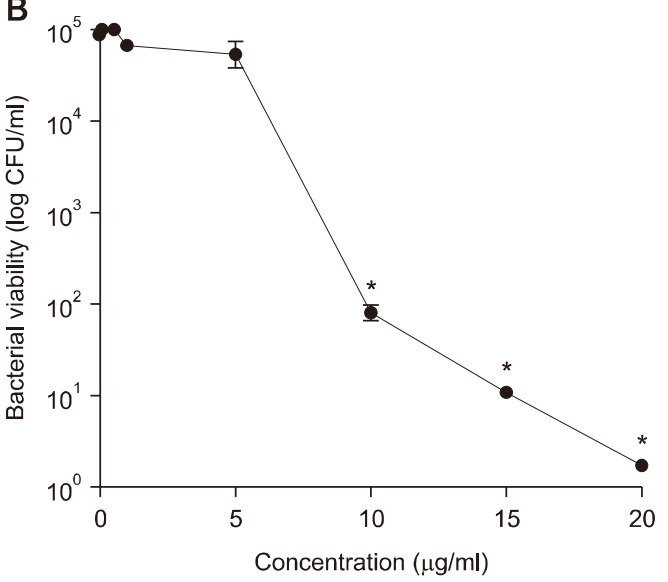

Fig. 1. Effects of the ethanol extract of Terminalia chebula (EETC) on Streptococcus mutans growth. (A) S. mutans $(0.1$ at $600 \mathrm{~nm})$ were cultured on brain-heart infusion agar plates with a paper disk containing the EETC. The diameters of the bacterial growth zone of inhibition were measured in millimeters $(\mathrm{mm})$. (B) The 10-fold diluted bacterial solution was cultured with the EETC and live cells on the agar plate were counted to measure colony-forming unit (CFU). ${ }^{*} p<0.001$ vs. CFU from $S$. mutans culture without the EETC.

Table 2. Anti-Bacterial Activity of Ethanol Extract of Terminalia chebula (EETC) against Streptococcus mutans

\begin{tabular}{lcccccc}
\hline & \multicolumn{5}{c}{ EETC concentration $(\mu \mathrm{g} / \mathrm{ml})$} \\
\cline { 2 - 6 } & 0 & 5 & 10 & 15 & 20 \\
\hline Diameter of clear zone $(\mathrm{mm})$ & $0.0 \pm 0.00$ & $1.7 \pm 0.12$ & $4.2 \pm 0.49$ & $10.1 \pm 0.72$ & $18.6 \pm 0.14$ \\
\hline
\end{tabular}


As shown in Fig. 2A, glucan formation was observed as a result of the reaction of sucrose and $S$. mutans culture filtrates, with increasing EETC concentrations inhibiting glucan formation. EETC concentrations of 1, 5, 10, and 15 $\mu \mathrm{g} / \mathrm{ml}$ resulted in $15,65,77$, and $91 \%$ reduction, respectively in glucan formation. The expression of GTase B ( $g t f B), g t f C, g t f D$, and fructosyltransferase $(f t f)$, which are involved in the formation of glucan and fructan, was observed by RT-PCR. As shown in Fig. 2B, increasing EETC concentration significantly reduced the gene expression levels of these four enzymes. This result indicated that a concentration lower than the MIC of $S$. mutans by the EETC inhibited glucan formation and related gene expression.

\section{Effect of the EETC on gingival epithelial cells}

The effect of EETC concentration on gingival epithelial cells was analyzed by the MTT assay. The cells were treated with 0 to $30 \mu \mathrm{g} / \mathrm{ml}$ EETC for 24 hours and 48 hours and live cells were analyzed. As shown in Fig. 3, cytotoxicity was not observed below $25 \mu \mathrm{g} / \mathrm{ml}$ EETC. However, cytotoxicity was observed at $30 \mu \mathrm{g} / \mathrm{ml}$ EETC. These data indicate that the required MBC of $20 \mu \mathrm{g} / \mathrm{ml}$ against $S$. mutans was safe for gingival epithelial cells.

\section{Discussion}

The long-term use of synthetic drugs, such as antibiotics, for the treatment of dental diseases creates antibioticresistant bacteria. Therefore, to prevent and treat oral diseases, studies have assessed the bacteriostatic or bactericidal effects of various natural plant extracts. Dental plaque is a representative biofilm formed on the enamel surface ${ }^{2)}$. Oral bacteria attached to the pellicle of the tooth surface produce extracellular substrate, such as glucan and fructan, thereby forming a structurally stable dental plaque combining heterogeneous bacterial cells ${ }^{2,10}$. Biofilm have a thick outer layer formed by insoluble
A

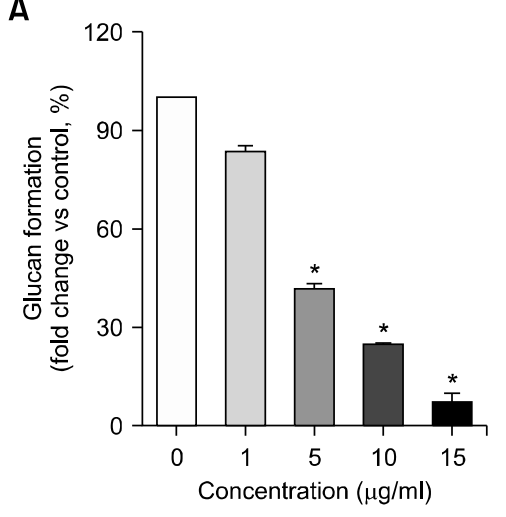

B

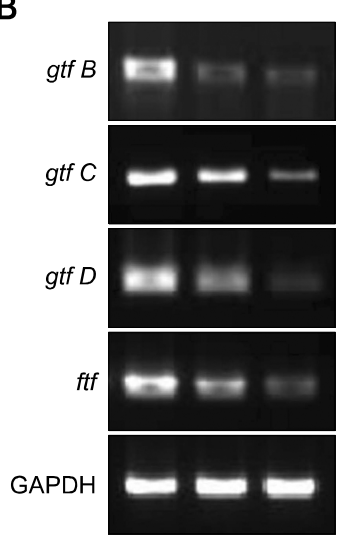

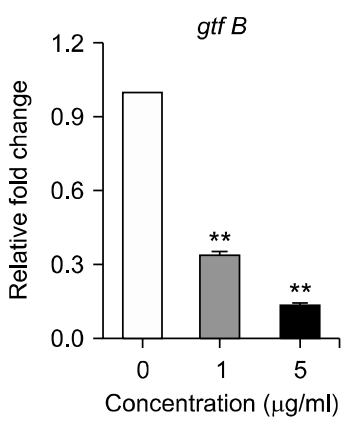

gtf $D$

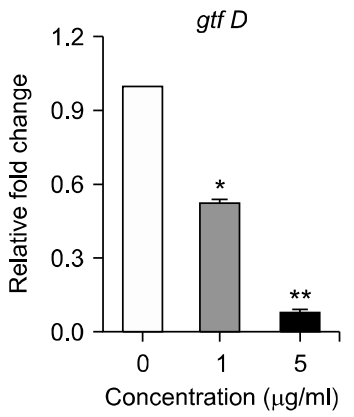

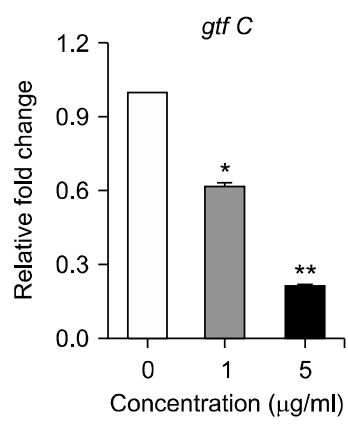

ftf

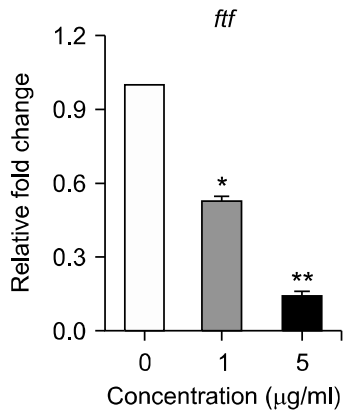

Fig. 2. Effects of the ethanol extract of Terminalia chebula (EETC) on glucan formation of gene expression in Streptococcus mutans. (A) The filtrate of $S$. mutans culture medium and sucrose were mixed and incubated for 36 hours at $37^{\circ} \mathrm{C}$. After centrifugation, the precipitate was sonicated and the absorbance was measured at $550 \mathrm{~nm} .{ }^{*} \mathrm{p}<0.001$ versus reaction with the filtrate from $S$. mutans culture without the EETC. (B) Reverse transcription-polymerase chain reaction (RT-PCR) was performed with primers for glycosyltransferase B $(g t f B)$, glycosyltransferase C ( $g t f C)$, glycosyltransferase D $(g t f D)$, and fructosyltransferase ( ftf). Gene expression was visualized by $2 \%$ agarose gel electrophoresis. Representative images from several experiments are shown. The images were captured and the density was measured using ImageJ software (National Institutes of Health, Bethesda, MD, USA). The relative densities were plotted as fold-changes. The values of the individual experiments are expressed as the mean \pm standard error of three independent experiments. ${ }^{*} p<0.05,{ }^{* *} p<0.001$ versus control. 


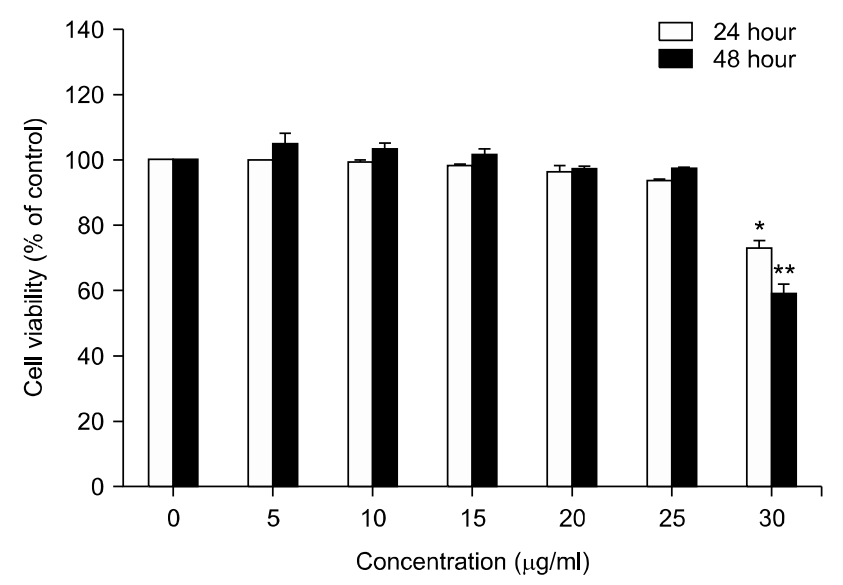

Fig. 3. Effect of the ethanol extract of Terminalia chebula (EETC) on cell cytotoxicity. Gingival epithelial cells were cultured with or without the EETC and live cells were analyzed using the 3-(4,5-dimethylthiazol-2-yl)-2,5-diphenyl tetrazolium bromide (MTT) assay. Cell viability is shown as \% of the control. The values of the individual experiments are expressed as the mean \pm standard error of three independent experiments. ${ }^{*} p<0.05,{ }^{* *} p<$ 0.001 versus control.

polymers, making penetration by external molecules difficult; moreover, bacterial genetic mutations are easily induced through cell-to-cell interactions, increasing bacterial resistance to antibiotics and antibacterial substances. Since the degree of deposition and maturity of the dental plaque is related to the severity of oral diseases, continuous management of dental plaques and maintenance of proper oral hygiene are important for the prevention of oral diseases. Scaling is an effective but temporary technique for dental plaques management. Since it is difficult to continue oral care for a long period, the development of effective antibacterial agent is necessary to reduce the number of bacteria that are responsible for oral diseases.

The results of this study demonstrated that the EETC was an effective antibacterial agent against dental cariescausative bacteria $S$. mutans. The antibacterial activity of EETC was confirmed by disc diffusion analysis and CFU measurement. The MIC and MBC of the EETC against $S$. mutans were $10 \mu \mathrm{g} / \mathrm{ml}$ and $20 \mu \mathrm{g} / \mathrm{ml}$, respectively. $T$. chebula (myrobalan) is widely used in traditional medicine in India and Iran for the treatment of dementia, constipation, and diabetes ${ }^{2)}$. Many of the beneficial effects of T. chebula fruit are related to the presence of various phytochemicals including steroids/sapogenins, saponins, anthraquinone derivatives, flavonoids, and tannins ${ }^{11,12)}$. The most important component in the fruit is tannins. $T$. chebula has a tannin content of 32 to $45 \%$ that including gallic acid, ellagic acid, chebulic acid, chebulinic acid, punicalagin, and tannic acid. The flavonoids quercetin, catechin, and kaempferol have been detected in T. chebula fruit $^{2}$. The fruit of the T. chebula has been extensively investigated for its medicinal value and has been used to treat cancer, cardiovascular diseases, paralysis, leprosy, ulcers, gout, arthritis, epilepsy, cough, fever, diarrhea, gastroenteritis, skin disorders, urinary tract infection, and wound infections ${ }^{12,13)}$. T. chebula fruit is also effective in the treatment of bacterial infection ${ }^{14,15)}$. Clinical trials of $T$. chebula fruit extract in a mouthwash preparation reported reduced plaque accumulation and gingival inflammation ${ }^{16,17)}$. Future research is needed to isolate various pure compounds from the $T$. chebula fruit extract and test them individually for medicinal purposes.

Herein, we also provide mechanistic details for the anticaries effects of EEDC. Since many studies on natural antibacterial agents have focused only on bacteriostatic and bactericidal analysis, biochemical and genetic analysis are generally poor, severely limiting the data available for understanding the antibacterial mechanisms of these various natural products. S. mutans is closely related to dental caries in that it forms extracellular polymers that contribute to the permanent colonization of hard surfaces by various bacteria, produce organic acids through glycolysis, and survive at low $\mathrm{pH}$ levels present in dental caries (aciduricity) ${ }^{18)}$. S. mutans produces three glucosyltransferases (GTFs; Gtf-B, Gtf-C, and Gtf-D) which utilize the glucose moiety of sucrose to synthesize glucose polymers of glucans through $\alpha(1-3)$ - and $\alpha(1-6)$-linkages. Additionally, the fructose moiety of sucrose produces lactic acid through glycolysis ${ }^{18)}$. The $\mathrm{ft} f \mathrm{~s}$ of $S$. mutans also catalyze the production of fructose polymers of fructans. Fructans serve as short-term extracellular carbohydrate sources and are degraded by the fructanase enzyme FruA, producing fructose, which can be utillized for energy synthesis. This process also produces organic acids. Therefore, GTFs are of vital importance for dental caries formation through their contributions to biofilm by forming a glue-like polysaccharide matrix and acid 
production. In this study, glucan formation was observed by the reaction of sucrose and $S$. mutans culture filtrate. However, EETC treatment significantly reduced glucan production. To investigate the mechanistic details of the extracellular insoluble polymers produced, we performed RT-PCR. Increasing the EETC concentration significantly reduced the gene expressions of $g t f \mathrm{~B}, g t f \mathrm{C}, g t f \mathrm{D}$, and $f t f$. Even at $10 \mu \mathrm{g} / \mathrm{ml}$ EETC, the MIC for S. mutans, a remarkable inhibition of the enzymes producing insoluble polymers was observed.

The results of this study suggested that the EETC had effective antibacterial activity against $S$. mutans and was safe for human gingival cells. Therefore, EETC can be applied in oral hygiene products to improve the management of dental caries. Further studies are required to isolate pure compounds related to the antibacterial activity of the EETC and are likely to yield improved antibacterial compounds for oral healthcare use.

\section{Notes}

\section{Conflict of interest}

No potential conflict of interest relevant to this article was reported.

\section{Ethical approval}

Not applicable.

\section{Author contributions}

Conceptualization: Young Sun Hwang. Data acquisition: Moonkyung Lee and Young Sun Hwang. Formal analysis: Moonkyung Lee and Young Sun Hwang. Funding: Young Sun Hwang. Supervision: Young Sun Hwang. Writingoriginal draft: Young Sun Hwang. Writing-review \& editing: Moonkyung Lee and Young Sun Hwang.

\section{ORCID}

Moonkyung Lee, https://orcid.org/0000-0003-1875-2596

Young Sun Hwang, https://orcid.org/0000-0001-7012-3434

\section{Acknowledgements}

This research was supported by Eulji University in 2021 and Basic Science Research Program through the National
Research Foundation of Korea (NRF) funded by the Ministry of Education, Science and Technology (20185R 1D1A1B07042035).

\section{References}

1. Health Insurance Review \& Assessment Service: Statistics of frequent disease in 2019. Retrieved February 12, 2021, from http://opendata.hira.or.kr/op/opc/olapHifrqSickInfo.do.

2. Lynch DJ, Michalek SM, Zhu M, Drake D, Qian F, Banas JA: Cariogenicity of Streptococcus mutans glucan-binding protein deletion mutants. Oral Health Dent Manag 12: 191-199, 2013.

3. Priya A, Kumar CBM, Valliammai A, Selvaraj A, Pandian SK: Usnic acid deteriorates acidogenicity, acidurance and glucose metabolism of Streptococcus mutans through downregulation of two-component signal transduction systems. Sci Rep 11: 1374, 2021. https://doi.org/10.1038/s41598-020-80338-6

4. Zhang G, Lu M, Liu R, et al.: Inhibition of Streptococcus mutans biofilm formation and virulence by Lactobacillus plantarum K41 isolated from traditional Sichuan pickles. Front Microbiol 11: 774, 2020. https://doi.org/10.3389/fmicb.2020.00774

5. Jokar A, Masoomi F, Sadeghpour O, Nassiri-Toosi M, Hamedi S: Potential therapeutic applications for Terminalia chebula in Iranian traditional medicine. J Tradit Chin Med 36: 250-254, 2016. https://doi.org/10.1016/s0254-6272(16)30035-8

6. Lee J, Nho YH, Yun SK, Hwang YS: Use of ethanol extracts of Terminalia chebula to prevent periodontal disease induced by dental plaque bacteria. BMC Complement Altern Med 17: 113, 2017. https://doi.org/10.1186/s12906-017-1619-1

7. Sharma C, Aneja KR, Kasera R, Aneja A: Antimicrobial potential of Terminalia chebula Retz. fruit extracts against ear pathogens. World J Otorhinolaryngol 2: 8-13, 2012. https://doi.org/10.5319/wjo.v2.i2.8

8. Nayak SS, Ankola AV, Metgud SC, Bolmal UK: An in vitro study to determine the effect of Terminalia chebula extract and its formulation on Streptococcus mutans. J Contemp Dent Pract 15: 278-282, 2014. https://doi.org/10.5005/jp-journals-10024-1528 
9. Illeperuma RP, Kim DK, Park YJ, et al.: Areca nut exposure increases secretion of tumor-promoting cytokines in gingival fibroblasts that trigger DNA damage in oral keratinocytes. Int J Cancer 137: 2545-2557, 2015.

https://doi.org/10.1002/ijc.29636

10. Do KY, Lee ES: Preventive effects of fluoride gel application on dental caries in the permanent tooth: a systematic review of randomized controlled trials. J Dent Hyg Sci 19: 9-22, 2019.

https://doi.org/10.17135/jdhs.2019.19.1.9

11. Lee HS, Jung SH, Yun BS, Lee KW: Isolation of chebulic acid from Terminalia chebula Retz. and its antioxidant effect in isolated rat hepatocytes. Arch Toxicol 81: 211-218, 2007. https://doi.org/10.1007/s00204-006-0139-4

12. Rathinamoorthy R, Thilagavathi G: Terminalia chebula review on pharmacological and biochemical studies. Int $\mathrm{J}$ Pharm Tech Res 6: 97-116, 2014.

13. Manosroi A, Jantrawut P, Ogihara E, et al.: Biological activities of phenolic compounds and triterpenoids from the galls of Terminalia chebula. Chem Biodivers 10: 1448-1463, 2013.

https://doi.org/10.1002/cbdv.201300149

14. Aneja KR, Joshi R: Evaluation of antimicrobial properties of fruit extracts of Terminalia chebula against dental caries pathogens. Jundishapur J Microbiol 2: 105-111, 2009.

15. Kim HG, Cho JH, Jeong EY, Lim JH, Lee SH, Lee HS: Growth-inhibiting activity of active component isolated from Terminalia chebula fruits against intestinal bacteria. J Food Prot 69: 2205-2209, 2006. https://doi.org/10.4315/0362-028x-69.9.2205

16. Naiktari RS, Gaonkar P, Gurav AN, Khiste SV: A randomized clinical trial to evaluate and compare the efficacy of triphala mouthwash with $0.2 \%$ chlorhexidine in hospitalized patients with periodontal diseases. J Periodontal Implant Sci 44: 134-140, 2014. https://doi.org/10.5051/jpis.2014.44.3.134

17. Gupta D, Gupta RK, Bhaskar DJ, Gupta V: Comparative evaluation of Terminalia chebula extract mouthwash and chlorhexidine mouthwash on plaque and gingival inflammation 4-week randomised control trial. Oral Health Prev Dent 13: 5-12, 2015. https://doi.org/10.3290/j.ohpd.a32994

18. Lemos JA, Burne RA: A model of efficiency: stress tolerance by Streptococcus mutans. Microbiology (Reading) 154(Pt 11): 3247-3255, 2008.

https://doi.org/10.1099/mic.0.2008/023770-0 